\title{
Financial Situation of Listed Companies in Pharmaceutical Industry
}

\author{
Haokun Yan Ting Xu \\ Guizhou university of finance and economics, Guiyang 550000, China
}

\begin{abstract}
This paper studies the financial risks of listed companies in China's pharmaceutical industry by means of qualitative research and quantitative research. Based on the financial data of Guizhou bailing pharmaceutical co, ltd. in 2015 and 2016. The empirical analysis shows that: Based on the fuzzy comprehensive evaluation method, the financial situation analysis of the listed companies in the pharmaceutical industry is feasible in the first year and the year of $T$. The financial status of listed companies in the pharmaceutical industry can be used to predict the financial risks of the pharmaceutical industry listed company $\mathrm{T} 1$ and 2 years.
\end{abstract}

\section{Keywords}

Pharmaceutical industry; Fuzzy comprehensive evaluation method; Risk warning

\section{医药行业上市公司财务状况研究}

\author{
严浩坤 徐婷 \\ 贵州财经大学, 贵阳 550025, 中国
}

摘要: 本文以定性研究和定量研究相结合的方法, 研究分析了我国医药行业上市公司的财务 风险。并以贵州百灵制药有限公司 2015 年和 2016 年的财务数据为基础, 对 T- 2 年和 T-1 年的财务状况进行了实证分析检验，验证模型构建的有效性。实证分析表明：基于模糊综合 评价法, 所构建的 T-1 年和 T-2 年医药行业上市公司财务状况分析具有较强的可行性; 医药 行业上市公司财务状况研究,可以用于预测医药行业上市公司 T-1 和 T-2 年的财务风险。

关键词：医药行业；模糊综合评价法；风险预警

\section{1. 引言}

在我国, 医药行业的发展速度已 经超过了 GDP 的增长速度, 成为当前 发展最快的行业之一。这些迅速崛起 的医药类上市公司既为投资者提供了 更为丰富的投资渠道，同时也为投资
者带来了更为多样化的投资风险组 合。上市公司财务风险最显著的特征 就是被 “特别处理（ST）”。企业财 务风险是从量发展到质变的过程, 而 企业财务风险的发生是可以预见的, 因此上市公司急需一套切实可行的系 统来预测财务状况。那么, 在医药行 业上市公司财务风险的特征的基础 
上, 来建立财务状况模型, 对建立主 要财务指标体系和科学的模型是否有 利? 能否准确地预测医药行业上市公 司的财务风险? 这对财务风险状况模 型的使用者、投资者、债权人、政府 监管机构以及债权人和其他利益相关 者是否具有重要的实际意义? 本文对 上述问题的研究具有相对来说比较重 要的理论和现实意义。

国外初期对于财务状况预警的研 究, 最早是由 Fitzpatrick 提出来的, 他 在 1932 年提出了单因素破产预测模 型; 而 Beaver 在 1966 年时，对 1965 年至 1953 年之间的 79 家失败企业和 相对应的 79 家成功企业为研究对象, 并对企业的 30 个财务指标进行了相应 的研究。自此, 为了克服前人模型的 缺陷, 又产生了其他的单变量模型, 大致有奢徒理论和资产负债分解模 型。爱德华经过大量实证在 1968 年提 出来采用多元线性判别法, 从而建立 了使用比较广泛的 $\mathrm{Z}$ 分数模型。然而 在我国, 预警模型则起步相对较晚。

1999 年, 陈静以 37 家 ST 公司, 27 家 非 ST 公司为数据样本, 利用它们一年 的财务报表数据, 并使用单变量和多 元判别分析方法进行了预测, 在此之 后, 陈晓、陈治鸿在 2000 年采用逻辑 回归模型, 在充分实验了几千种变量 组合后, 总结了几个财务指标的显著 地预测作用。郑茂（2003）则采用具 有说服力的财务数据组合, 以此来构 建财务状况预测模型, 以此来增强研 究结果的说服力。这个模型的精确度 比以前研究中的模型有了很大的提 高。基于上述文献，本文将对 20152016 年沪深两市医药行业的 ST 和非 ST 公司的样本数据进行建模, 利用 SPSS 软件进行因子分析, 建立一个子 集。并使用用模糊综合评价法, 构建 了我国医药行业上市公司 T-1 年和 T-2 年的财务状况预测模型。最后以贵州 省上市公司中医药行业类企业中的代
表性企业贵州百灵作为检验样本，检 验模型的有效性。

我国上市公司财务状况预测系统并 没有在实践中得到广泛的应用, 这当 中原因大概有以下几个方面：1、各行 各业上市公司的管理层缺乏利用财务 预警系统提前化解风险的意识; 2、行 业财务状况预警系统的设计不注重其 具体的实用性； 3、行业财务状况预警 模型的设计, 在样本选择上有一定的 局限性; 4、企业财务数据的作假, 直 接影响了预警系统的有效性。

本文结构安排如下: 第二部分为研 究设计。第三部分为是实证检验。通 过选取贵州省医药行业中有代表性的 上市公司贵州百灵药业 2015 年、2016 年的财务数据，检验财务状况预警模 型的有效性; 第四部分为结论。

\section{2. 研究设计}

本文以我国医药行业的上市公司 为数据样本, 并以各公司财务指标为变 量, 以此来构建财务状况预警模型。 构建模型的同时，先对本文作出以下 4 各方面假设条件：1、医药行业上市公 司的财务风险是可以预测的；2、医药 行业上市公司财务预警模型的会计信 息是真实可信的; 3 、医药行业上市公 司的盈利能力、偿债能力、资产运营 能力等和财务风险发生概率为负相 关； 4、医药行业上市公司的资产结构 与财务风险发生概率互为正相关。

本文选取了中国沪深两市所有的 医药行业上市公司 2015 年 156 家公司 和 2016 年 165 家公司的 17 项财务指标 数据（删除了数据缺失公司）, 财务 指标分别有 X1 总资产利润率、X2 净 资产收益率、X3 每股收益、X4 流动比 率、X5 营运资本总资产比率、X6 资产 负债比率、 $\mathrm{X} 7$ 存货周转率、 $\mathrm{X} 8$ 应收账 款周转率、X9 流动资产周转率、X10 总资产周转率、X11 主营业务收入增 
长率、X12 营业利润增长率、X13 净资 产增长率、X14 总资产增长率、X15 经 营性现金流量债务总额比、X16 总资 产、X17 固定资产与总资产比率，并 分别从企业的盈利能力、偿债能力、 资产营运能力、成长能力、资本结构 和现金流量这六个方面进行了评价。 通过因子分析和归一化处理, 得出了 $\mathrm{T}-2$ 年的 6 个能力因子的权重:

偿债能力因子 $\mathrm{u} 1$ $=28.0 \% \mathrm{X} 4+23 \% \mathrm{X} 5+25 \% \mathrm{X} 15+24 \% \mathrm{X} 6$ 盈利能力因子 $\mathrm{u} 2$ $=22 \% \mathrm{X} 16+26 \% \mathrm{X} 2+28 \% \mathrm{X} 3+24 \% \mathrm{X} 1$ 资产营运能力因子 $\mathrm{u} 3$ $=28 \% \mathrm{X} 10+23 \% \mathrm{X} 9+24 \% \mathrm{X} 7+25 \% \mathrm{X} 11$ 成长能力因子 $\mathrm{u} 4$ $=46 \% \mathrm{X} 13+46 \% \mathrm{X} 14+0.08 \% \mathrm{X} 17$ 总资产增长能力因子 u5 $=56 \% \mathrm{X} 12+44 \% \mathrm{X} 17$

现金因子 $u 6=38 \% X 16+62 \% X 8$ 通过因子分析, 提取 $\mathrm{T}-1$ 年医药行 业上市公司财务状况预警初选指标的 6 个公共因子,各公共因子的比例如下： 偿债能力因子 u1 $=28 \% \mathrm{X} 6+26 \% \mathrm{X} 5+25 \% \mathrm{X} 4+21 \% \mathrm{X} 15$ 盈利能力因子 $\mathrm{u} 2$ $=36 \% \mathrm{X} 2+34 \% \mathrm{X} 3+30 \% \mathrm{X} 1$

资产营运能力因子 $\mathrm{u} 3$ $=41 \% \times 7+31 \% \times 10+28 \% \times 9$ 总资产增长能力因子 $\mathrm{u} 4$ $=51 \% \mathrm{X} 13+49 \% \mathrm{X} 14$ 成长能力因子 $\mathrm{u} 5=50 \% \mathrm{X} 12+50 \% \mathrm{X} 11$ 现金因子 $u 6=52 \% \mathrm{X} 16+48 \% \mathrm{X} 8$

如上所述的公共因子为建立基于 模糊综合评价法的预警模型奠定了基 础。其中构建的 T-2 年医药行业上市 公司财务状况预警模型是以 2015 年我 国医药行业上市公司财务数据为基础 的。模糊综合评价法的模型由评价对 象的因子集 $\mathrm{U}$ 、评价集 $\mathrm{V}$ 、权重集 $\mathrm{A}$ 以及隶属度函数等组成。权重集 $\mathrm{A}=$

( 0.2148,0.2044,0.2015,0.1694,0.1538,0. 0427）通过以上所述的分析和统计以 及选择的公共因子,以此来构建 $\mathrm{T}-2$ 年
医药行业上市公司财务状况预警模 型: $M=A * R$

(1)通过对 T-2(2015)年的财务数据 的分析, 可以得到结果, 医药行业财务 状况预警模型 $\mathrm{M}$ 的计算结果是一个在 隶属度数值的矩阵中的最大值。

(2)相比较于评价集的最大隶属度, 该隶属度数字的最大值对应于这 9 个 评价等级中的某一个。评价集为 $\mathrm{V}=\{$ 非常好, 很好, 好, 比较好, 一般, 比较 差, 差, 很差, 非常差\}, 以此来查找隶属度 最大的数字所对应的评价等级。

(3)医药行业上市公司的财务状况 程度是根据上述计算出来的矩阵中的 最大数量的评估数字确定的。当该最 大值的隶属度数对应的评价等级分别 为非常好、很好、好、比较好、一般 这五种情况当中之一的时候,则说明该 公司暂时是没有财务状况风险的，而 当相应评价等级的最大隶属度分别比 较差时, 表示该公司目前面临着有财 务状况问题的可能性,出于财务上的谨 慎原则, 本文将比较差列入有财务状况 有问题的范畴; 当计算出的最大值的 隶属度数对应的评价等级分别为差、 很差、非常差这最后的三种情况时,则 表示该公司财务状况存在风险。至 此, 综上所构建的该模型可以为医药 行业内的任意一家公司准确评估其财 务状况, 并为其提供财务状况的预警 信息。

同时要建立 T-2 年的财务状况预 警模型, 因此以 2016 年制药行业上市 公司的财务数据为基础, 同样的通过 如上所述分析, 构建了 T-1 年医药行 业上市公司财务状况预警模型：

$\mathrm{M}=\mathrm{A} * \mathrm{R}$, 权 重 集 $\mathrm{A}=$ ( 0.18182,0.15909,0.20455,0.20455,0.11 $363,0.13636)$ 评价结果分析原理同 T-2 (2015) 年的结果分析,在此不再赘 述。 


\section{3. 实证检验}

从贵州省医药上市公司选择典型 的贵州百灵集团制药有限公司, 并根 据相关的财务数据, 利用 6 个公共因 子所需的财务数据, 建立了贵州百灵 企业 T-2 年的财务状况预警计量的因 子集。由因子分析提取的 6 个公共因 子建立的因子集 U, 下面是贵州百灵 财务状况预警计量的因子集的构成比 例:

偿债能力因子 $\mathrm{u} 1$

$=28.0 \% \mathrm{X} 4+23 \% \mathrm{X} 5+25 \% \mathrm{X} 15+24 \% \mathrm{X} 6$

盈利能力因子 $\mathrm{u} 2$

$=22 \% \mathrm{X} 16+26 \% \mathrm{X} 2+28 \% \mathrm{X} 3+24 \% \mathrm{X} 1$

资产营运能力因子 u3

$=28 \% \mathrm{X} 10+23 \% \mathrm{X} 9+24 \% \mathrm{X} 7+25 \% \mathrm{X} 11$

成长能力因子 $\mathrm{u} 4$

$=46 \% \mathrm{X} 13+46 \% \mathrm{X} 14+0.08 \% \mathrm{X} 17$

总资产增长因子 $\mathrm{u} 5=56 \% \mathrm{X} 12+44 \% \mathrm{X} 17$

现金因子 $\mathrm{u} 6=38 \% \mathrm{X} 16+62 \% \mathrm{X} 8$

本着严谨的态度, 本文将偿债能 力因子、盈利能力因子、资产营运能 力因子、总资产增长能力因子、成长 能力因子、现金因子划分了 9 各等 级, 因此评价集 $\mathrm{V}$ 为:

评价集 $\mathrm{V}=\{$ 非常好、很好、好、比较 好、一般、比较差、差、很差、非常 差\}

紧接着是要建立贵州百灵药业股 份有限公司财务状况预警模糊综合评 价矩阵, 所有权重相加等于 1 , 模型的 权重集为 $\mathrm{A}=(0.18182,0.15909,0.20455$, $0.11363,0.13636)$. 根据综合评价模型所 建立的方法, 可以得到最终的综合评 价矩阵为: $\mathrm{M}=\mathrm{A} * \mathrm{R}=(0.18182,0.15909$, 0.20455 , 0.11363 , $0.13636) * \mathrm{R}=(0.01787,0.34089, \quad 0.07633$, $0.06184, \quad 0.14945,0.06238,0.11198$, $0.09471,0.04865)$

根据如上所述的计算结果, 最终 确定了依据该公司 2015 年财务数据计 算出来的模糊综合评价矩阵 $\mathrm{M}=(0.01787,0.34089,0.07633,0.06184$,
$0.14945, \quad 0.06238,0.11198,0.09471$, 0.04865)。其中, 隶属度最大值为 0.34089 。根据所计算出的结果, 有效 地查询评价集 $\mathrm{V}=\{$ 非常好, 很好, 好, 比较 好,一般,比较差,差,很差, 非常差\}, 很明 显可以看出最大值 0.34089 所对应的评 价等级为很好, 那么该公司的财务水 平是非常好, 而且, 其很好的隶属度 最高,达到 0.34089 。同理, 利用 T-1 年 预警模型计算了该公司 2016 年的模糊 综合评价矩阵 $\mathrm{M}=(0.11063,0.20947$, $0.14538,0.18364,0.13065,0.04118$, $0.07942,0.03591,0.04783)$ 其中隶属度 最大值为 0.20947 , 查询评价集可知, 该公司的财务状况处于比较好的状 态, 其比较好的隶属度最高, 达到了 0.20947 。

利用上述财务状况预警模型，对 该公司 2015、2016 年的财务预警结果 分析为非常好、很好,而对比 2016 年证 券市场上该公司的经营业绩和实际情 况, 该公司没有被 ST, 由此结果可知 本文建立的财务预警模型是有效的。

综上所述，通过本文实例贵州百 灵药业股份有限公司财务状况预警模 型的应用，说明基于模糊综合评价法 的医药行业上市公司财务状况预警模 型是有效的。首先,对医药行业上市公 司财务状况预警模型进行定量分析, 同时该模型能够较好的预警企业的风 险状况, 为公司管理决策人员提供有 效参考。

\section{4. 结论}

本文建立的医药行业上市公司财 务状况预警模型是基于模糊综合评价 方法之上建立的。本文的主要结论如 下:

1、根据贵州百灵药业股份有限公 司 2015、2016 年的财务数据进行实证 分析, 基于模糊综合评价法建立的 T-1 
年和 T-2 年医药行业上市公司财务状 况预警模型是有效的。

2、本文所建立的 T-1 年和 T-2 年 医药行业上市公司财务状况预警模 型, 可以用来预测医药行业上市公司 $\mathrm{T}-1 、 \mathrm{~T}-2$ 年的财务状况风险, 比如 说，输入任何一个医药行业内的上市 公司的 2015、2016 年财务数据，可以 预测出该公司 2015、2016年的财务风 险。本文选取的样本数据是基于我国 深沪两市 $\mathrm{A}$ 股市场医药行业的上市公 司数据, 这样可以避免某一特定行业 的影响因素, 这就意味着该模型比较 有针对性, 具有较强的行业应用意 义。

\section{参考文献}

[1] Karen A. Joreher., Essential of Financial Risk Management, Economic sciences press, Beijing, 2006.

[2] 陈舒航, 基于模糊综合评价的房地 产企业财务风险研究, 财会研究, 4:43-45， 2010.

[3] 俄召娣, 高科技企业财务危机预警 模型构建, 生产力研究, 13:1719， 2012.

[4] 张亚明, 王伟志, 罗涁, 房地产上 市公司的财务风险预警研究, 中国 商贸， 1:52-55，2015. 